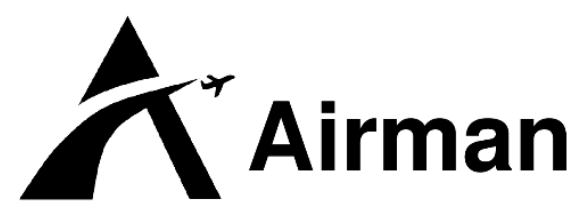

Jurnal Teknik dan Keselamatan Transportasi

\title{
Rancang Bangun Remote-Control Monitoring System (RCMS) pada peralatan Navigasi Udara NDB di Makassar Air Traffic Service Center berbasis Internet of Thing (IoT)
}

\section{Design of Remote-Control Monitoring System (RCMS) for NDB Air Navigation equipment in Makassar Air Traffic Service Center based on Internet of Thing (IoT)}

\author{
Bayu Purbo $\mathrm{W}^{1^{*}}$, Gatot Kuswara ${ }^{2}$, M Roby Syaritno ${ }^{3,}$ Ucok Sinaga $^{4}$ \\ bayu.purbo@poltekbangmakassar.ac.id.,gatkuspim4@gmail.com, mrsyaritno@gmail.com, \\ Iotmakassar@gmail.com \\ ${ }^{1}$ Politeknik Penerbangan Makassar, ${ }^{2}$ Politeknik Penerbangan Makassar \\ ${ }^{3}$ Airnav Indonesia (Makassar Air Traffic Service Center), ${ }^{4}$ Universitas Indonesia Timur
}

\begin{abstract}
ABSTRAK
"Rancang Bangun Remote Control Monitoring System (RCMS) pada peralatan Navigasi Udara $N D B$ di Cluster Cabang Makassar (MATSC) Berbasis Internet of Thing (IoT)”. Manfaat RCMS diantaranya yaitu; Dapat membantu teknisi pelaksana pemeliharaan dalam pelaksanaan tugas pemeliharaan level pada tertentu, Sebagai wujud sinergi dan kolaborasi dunia industri penerbangan dengan pendidikan vokasi, Dengan adanya $R C M S$ ini maka akan diperoleh data yang lebih baik bagi penelitian lebih lanjut. Tujuaan perancangan ini yaitu ; Merancang sebuah Remote Control and Monitoring System (RCMS) untuk NDB Hanjin KMW 250 RB, Mengimplementasikan keilmuan dan teknologi sebagai wujud Kolaborasi dunia pendidikan dengan industri penerbangan, Menyediakan data pemeliharaan peralatan untuk keperluan maintenance management. Dan di control langsung di ruang teknisi untuk mempermudah memonitoring Peralatan Navigasi NDB. Metode perancangan ini berbasis Internet of Thing (IOT). Hasil rancangan ini mampu memberikan tampilan mengenai parameter pada peralatan Navigasi Udara (NDB) di Cabang Makassar (MATSC).
\end{abstract}

Kata kunci: $R C M S$; $N D B$ dan $I o T$

\section{ABSTRACT}

"Design of Remote-Control Monitoring System (RCMS) on NDB Air Navigation equipment in Makassar Branch Cluster (MATSC) based on Internet of Thing (IoT)". The benefits of RCMS include; Can assist maintenance technicians in carrying out maintenance tasks at a certain level, as a form of synergy and collaboration between the aviation industry and vocational education, with this RCMS, better data will be obtained for further research. The objectives of this design are; Designing a Remote Control and Monitoring System (RCMS) for NDB Hanjin KMW 250 RB, implementing science and technology as a form of collaboration between the education world and the aviation industry, Providing equipment maintenance data for maintenance management purposes. And in control directly in the technician's room to make it easier to monitor NDB Navigation Equipment. This design method is based on the Internet of Thing (IoT) The results of this design are able to provide a display of the parameters of the Air Navigation Equipment (NDB) in the Makassar Branch (MATSC),

Keywords: RCMS; NDB and IoT 


\section{PENDAhUluan}

\subsection{Latar Belakang}

Airnav Indonesia adalah perusahan BUMN yang bergerak dibidang pelayanan navigasi penerbangan. Airnav Indonesia memiliki beberapa cabang dibawahnya salah satunya adalah Cabang Makassar (MATSC / MakassarAir Traffic Secvice Center), di Cabang MATSC sendiri memiliki cluster binaan dibawahnya yaitu UPNP (Unit Pelayanan Navigasi Penerbangan) Palopo, Masamba, Bone, Toraja, Mamasa, Seko, Rampi, Palu, Mamuju, Poso, Luwuk, Ampana, Toli-toli, Selayar, dan Buol. Di antara 15 UPNP tersebut ada 12 lokasi yang memiliki peralatan navigasi udara berupa NDB dan di antara ke 12 lokasi tersebut ada 8 lokasi yang tidak memiliki teknisi navigasi dilokasinya, sehingga menimbulkan ancaman dan risiko kegagalan serta performance peralatan tidak mencapai level quality dan safety yang diinginkan atau disepakati, Seiring dengan perkembangan teknologi, berbagai peralatan navigasi telah berbasis komputerisasi, sehingga lebih memudahkan untuk memonitoring peralatan(Jamaluddin Rahim, junaedi, 2018).

NDB (Non-Directional Beacon) adalah fasilitas navigasi penerbangan yang bekerja dengan menggunakan frekuensi rendah (low frequency) dan dipasang pada suatu lokasi tertentu di dalam atau di luar lingkungan bandar udara sesuai fungsinya. (SKEP/113/11/2002) Dimana peralatan NDB Hanjin KMW 250 RB ini masih berupa analog dan belum disediakan interface untuk mengontrol dari jarak jauh. Untuk memberikan pelayanan navigasi penerbangan yang berkualitas, aman dan memenuhi standar maka harus didukung dengan sumber daya manusia yang handal dan kinerja peralatan yang mumpuni dan bersifat redundant. Kondisi sumber daya manusia (SDM) di MATSC khususnya di unit navigasi sangat minim, jumlah SDM di divisi navigasi dan survaillence hanya berjumlah 22 orang dan ini sangat jauh dari kondisi ideal sesuai dengan Keputusan Pemerintah No 25 tahun 2014. Perbandingan jumlah fasilitas navigasi penerbangan yang dimiliki oleh MATSC dengan jumlah SDM yang menangani fasilitas tersebut sangat timpang dan nantinya timbulnya ancaman dan risiko kegagalan serta performance peralatan tidak mencapai level quality dan safety yang diinginkan atau disepakati. Akibatnya proses pemeliharaan dan perawatan peralatan fasilitas navigasi penerbangan tidak berjalan sesuai dengan aturan di KP 35 tahun 2019.

Kekurangan SDM di unit navigasi sangat mempengaruhi nilai availaibility peralatan dan dapat menimbulkan potensi hazard di kemudian hari. Hal ini dapat membuat Level Of Service dari peralatan akan menurun dan mempengaruhi safety di unit navigasi. Hal ini tentunya tidak diharapkan oleh manajemen Airnav Indonesia karena tidak sejalan dengan visi dan misi perusahaan yang mengedepankan keselamatan penerbangan. Sehingga perlu dibuat sebuah terobosan atau ide yang dapat mengantisipasi sementara kekurangan personel agar pemeliharaan fasilitas navigasi tetap berjalan sesuai dengan aturan Perkembangan teknologi ini pun telah melalui perubahan yang cukup signifikan dari tiap generasi,terbukti dengan munculnya berbagai macam perangkat telekomunikasi dengan teknologi tingkat tinggi. Munculnya teknologi telekomunikasi yang lebih canggih dari sebelumnya dapat memecahkan masalah yang dihadapi dan diselesaikan dalam waktu yang cepat dan singkat (Abdul Azis ,Rio Setiawan) .

RCMS adalah suatu sistem yang dapat digunakan untuk mengontrol dan memonitoring kondisi peralatan dari jarak jauh, artinya kinerja peralatan dapat dipantau dari mana saja melalui jaringan komunikasi data yang terhubung ke peralatan tersebut secara real time. Disini RCMS tersebut digunakan untuk melakukan monitoring pancaran NDB berdasarkan SKEP/83/VI/2005 yaitu berupa pembacaan arus, tegangan, daya, 
modulasi, suhu, change over, dan kondisi lingkungan serta pengimplementasian di teknologi IOT, dimana IOT merupakan suatu konsep yang bertujuan untuk memperluas manfaat dari konektivitas internet yang tersambung secara terus menerus. (Arafat, M. K. 2016)

Oleh sebab itu peneliti mempunyai ide dan terobosan bagaimana cara mengatasi hal tersebut melalui suatu rancangan "Rancang

Bangun Remote Control Monitoring System (RCMS) pada peralatan Navigasi Udara NDB di Cluster Cabang Makassar (MATSC) berbasis Internet of Thing (IoT). Hal ini tentunya diharapkan dapat mengatasi sementara kekurangan SDM di unit navigasi penerbangan agar proses perawatan, monitoring dan pengecekkan peralatan navigasi NDB di cluster MATSC tetap terkontrol dan terpantau seluruhnya agar meningkatkan quality performance peralatan dan menjamin safety akan keberadan peralatan navigasi penerbangan di MATSC serta sejalan dengan visi dan misi perusahaan Airnav Indonesia.

Berdasarkan latar belakang di atas, maka yang menjadi rumusan masalah dalam penelitian ini adalah,apa saja parameter yang akan diambil untuk RCMS NDB Hanjin KMW250 RB tersebut ?, Bagaimana unjuk kerja sensor dan aktuator pada implementasi remote control monitoring system diiperalatan Navigasi Udara (NDB) ?, Bagaimana performance RCMS pada implementasi di teknologi IOT ?

Beberapa batasan yang dapat ditentukan pada penelitian ini antara lain, Sensor dan kontroller yang digunakan disesuaikan dengan parameter pengukuran yang terdapat pada peralatan NDB, Peralatan yang dimonitoring ini digunakan untuk NDB Hanjin KMW 250 RB.

Berdasarkan Batasan Masalah diatas maka tujuan masalahnya antara lain Merancang sebuah Remote Control and Monitoring
System (RCMS) untuk NDB Hanjin KMW 250 RB, Mengimplementasikan keilmuan dan teknologi sebagai wujud Kolaborasi dunia pendidikan dengan industri penerbangan., Menyediakan data pemeliharaan peralatan untuk keperluan maintenance management.

Manfaat yang didapat pada penelitian ini antara lain dengan tersedianya RCMS dapat membantu teknisi pelaksana pemeliharaan dalam pelaksanaan tugas pemeliharaan level tertentu, Sebagai wujud sinergi dan kolaborasi dunia industri penerbangan dengan pendidikan vokasi , Dengan adanya RCMS ini maka akan diperoleh data yang lebih baik bagi penelitian lebih lanjut.

\section{METODE}

Teknik atau metode yang digunakan dalam pengumpulan data yaitu metode pustaka dengan cara mengumpulkan beberapa data tertulis baik dari buku, literatur, dan tutorialtutorial di internet, sebagai bahan referensi penyusunan penelitian, kemudian mencocokkan dengan kemungkinankemungkinan yang terjadi dalam penyelesaian masalah.

\section{a. Waktu dan Tempat Penelitian}

Penelitian ini dilaksanakan dari bulan Juni sampai dengan September 2020 di AIRNAV Cabang MATSC dan Iot Lab CV. Mitra Karya Informatika

\section{b. Jadwal Penelitian}

Penelitian dilakukan dimulai dari mulai bulan juli 2019 sampai dengan oktober 2019 dimana persiapan dari bulan juli, perancangan dari bulan juli sampai agustus, desain bulan juli sampai agustus, implementasi juli sampai September, operasional bulan juli sampai juli sampai oktober, optimaliasasi bulan agustus sampai oktober, penulisan laporan di agustus sampai oktober.berikut table jadwal penelitian 
Airman: Jurnal Teknik dan Keselamatan Transportasi

Volume 3 Nomor 2 Desember 2020

P-ISSN 2622 - 0105 | E-ISSN 2716-1196

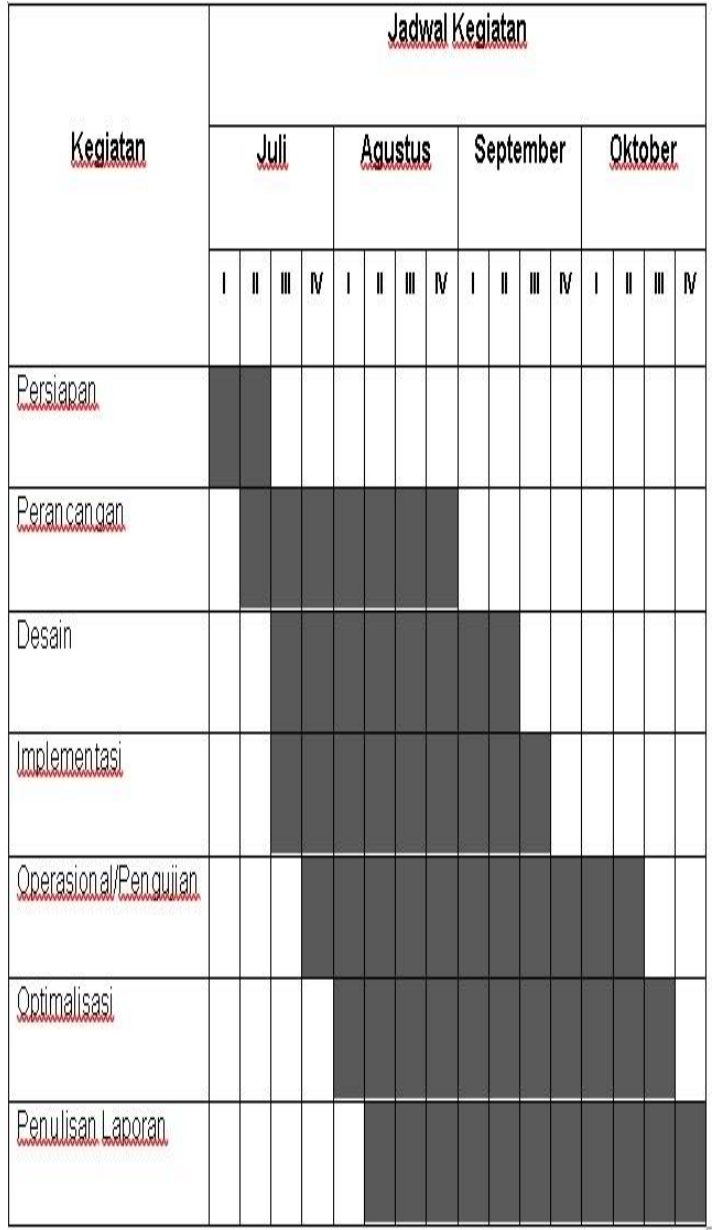

Tabel 1. jadwal penelitian

\section{c. Instrumen Pengumpulan Data}

Pengumpulan data membutuhkan suatu instrumen. Instrumen ini dibutuhkan untuk pengambilan data untuk penelitian baik penelitian kualitatif maupun penelitian kuantitatif. Instrumen penelitian adalah alat atau fasilitas yang digunakan oleh peneliti dalam mengumpulkan data agar pekerjaannya lebih mudah dan hasilnya lebih baik dalam arti lebih cermat, lengkap, dan sistematis sehingga lebih mudah diolah.

\section{d. Jenis penelitian}

Jenis penelitian yang digunakan oleh penulis dalam penelitian ini adalah penelitian experimental dengan pendekatan. Metodologi PPDIOO. Penelitian ini dilakukan dengan cara melakukan uji coba dimana rancangan mekanik maupun elektronika untuk komponen hardware rancang bangun alat menggunakan sensor ini dapat bekerja sesuai dengan tujuan dan target yang diinginkan.

Secara garis besar alur penelitian menggunakan pendekatan Metodologi PPDIOO dimana tahapahan dalam proses penelitian dimulai dari tahap persiapan, tahap perencanaan, desain, implementasi, pengoperasioan dan optimalisasi. Adapun rincian alur penelitian yang direncanakan tampak pada gambar dibawah ini :

\section{Gambar 1. Metodologi penelitian}

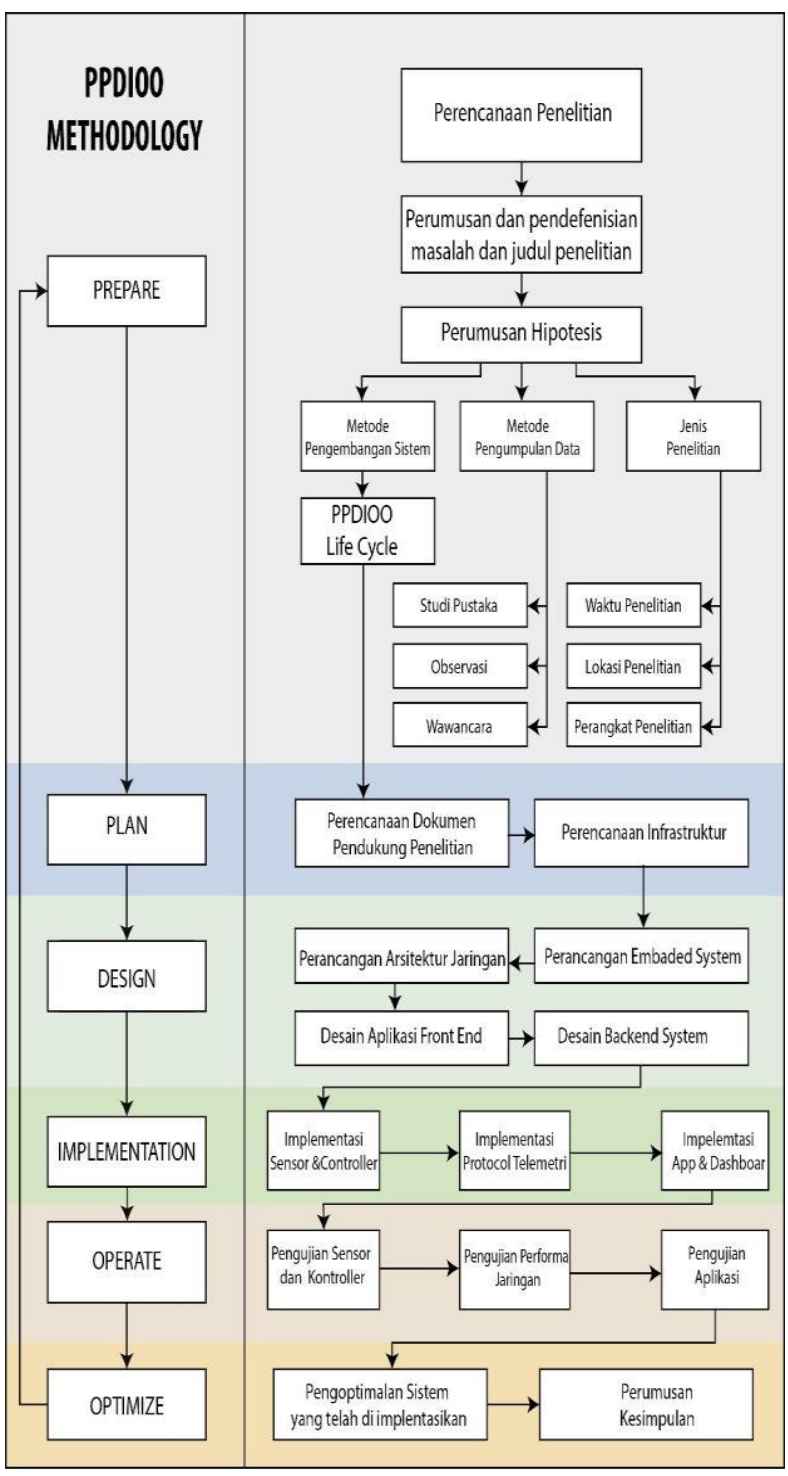

\section{HASIL DAN PEMBAHASAN}

Hasil dari penelitian ini berupa suatu sistem yang terdiri dari perangkat keras dan perangkat lunak untuk melakukan monitoring peralatan 
NDB Hanjin KMW 250 RB, berikut blok diagram system yang dibuat :

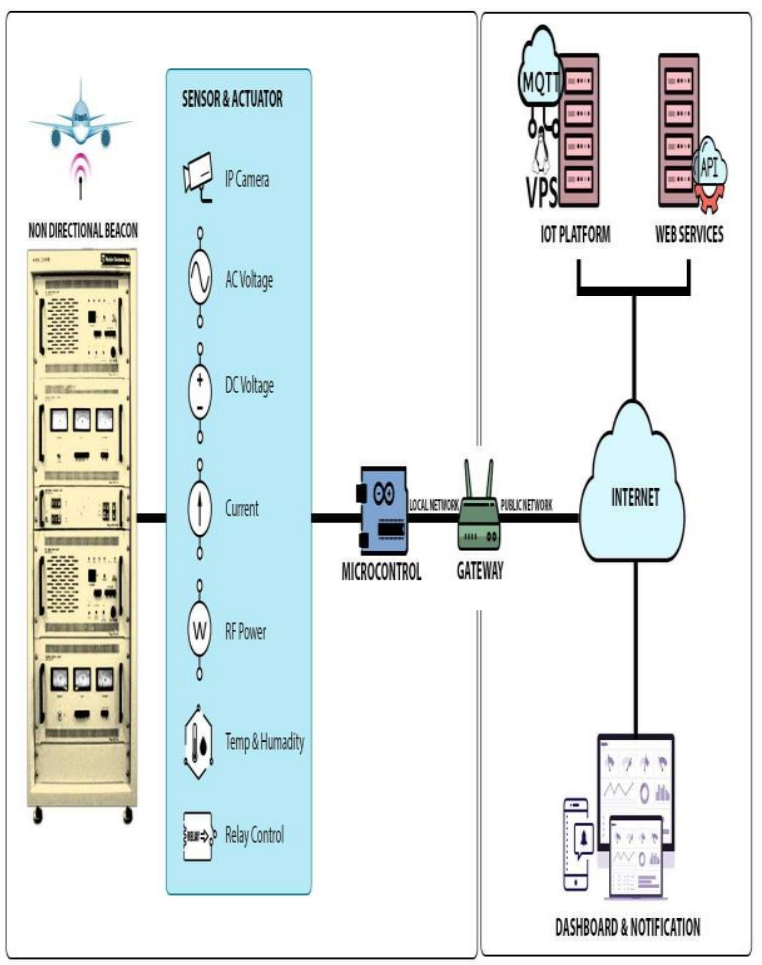

\section{Gambar 2. Blok diagram sistem}

\subsection{Implentasi Hardware}

Dari sisi perangkat keras, alat yang dihasilkan ikemas dengan enclosure box yang didalamnya terdiri dari sensor untuk mendeteksi beberapa parameter yaitu tegangan $24 \mathrm{Vdc}, 15$ Vdc, -15 Vdc, - 72 Vac, 220 Vac, arus, suhu dan kelembaban, dan untuk mengendalikan transmitter digunakan relay, berhubung perangkat NDB Hanjin KMW 250 RB yang berada di MATSC hanya single transmiter (TX1) maka transmiter ke 2 (TX2) disimulasikan dengan lampu. Tahapan awal dilakukan instalasi rangkaian voltage divider pada papan PCB untuk mengukur parameter tegangan, selanjutnya semua sensor dihubungkan dengan microkontroller yang sudah terprogram seperti gambar dibawah ini.

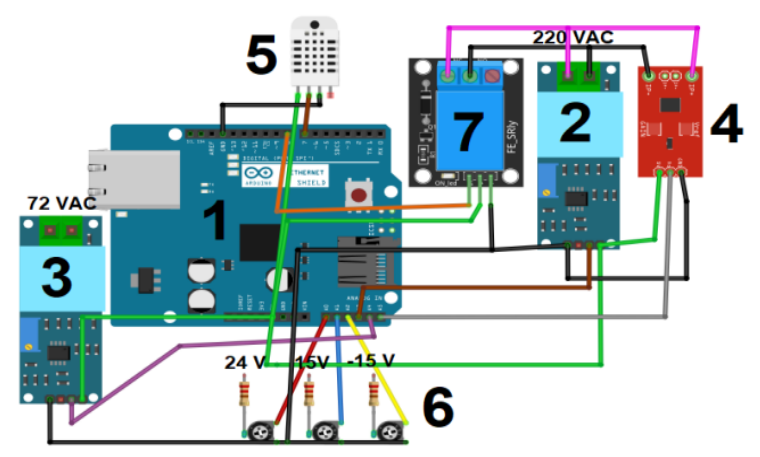

Gambar 3. Rangkaian Desain RCMS

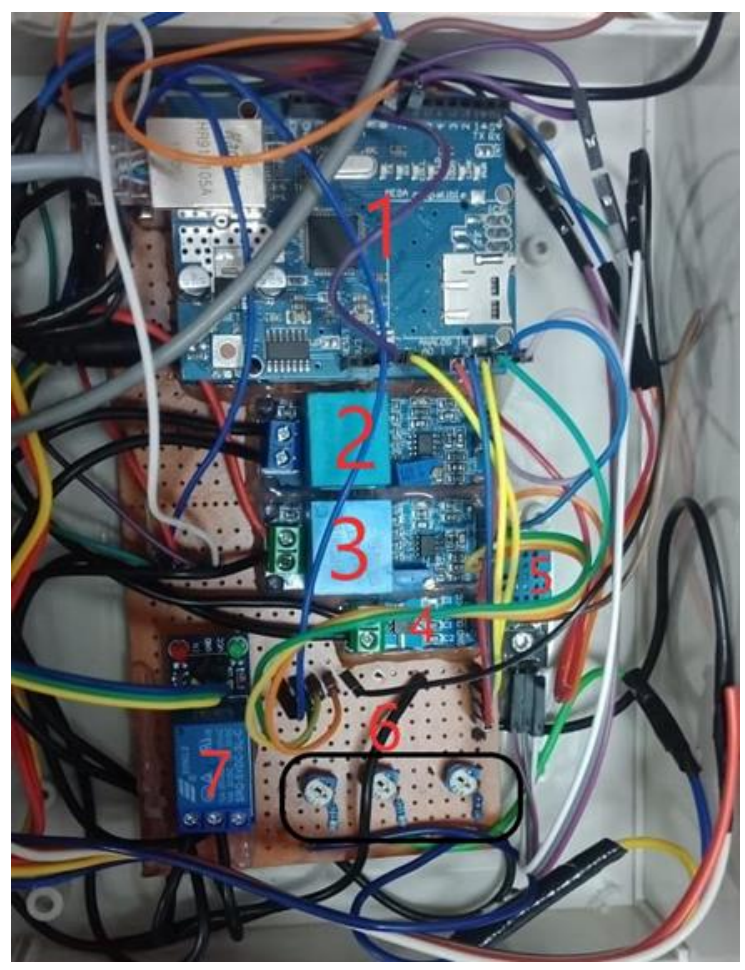

Gambar 4. Implementasi Modul RCMS

Keterangan pada gambar 3 sebagai berikut

- Nomor 1 menujukkan modul arduino uno yang sudah terinstall dan terprogram.

- Nomor 2 dan 3 menunjukkan sensor tegangan AC dimana untuk mendeteksi tegangan 220 Vac dan -72 Vac.

- Nomor 4 menunjukkan sensor arus untuk mendeteksi arus atau beban yang digunakan.

- Nomor 5 menunjukkan sensor DHT 11 untuk mendeteksi suhu dan kelembaban. 
- Nomor 6 menujukkan rangkaian voltage divider dimana untuk mendeteksi tegangan $24 \mathrm{Vdc}, 15 \mathrm{Vdc},-15 \mathrm{Vdc}$.

- Nomor 7 menunjukkan modul relay yang berfungsi untuk melakukan perpindahan transmitter (Change over TX).

\subsection{Implementasi Software}

\subsubsection{Menjalankan Node Red}

Melakukan installer node.js pada website resminya, setelah melakukan installer maka selanjutnya buka command prompt ketik npm install -g --unsafe-perm node-red.

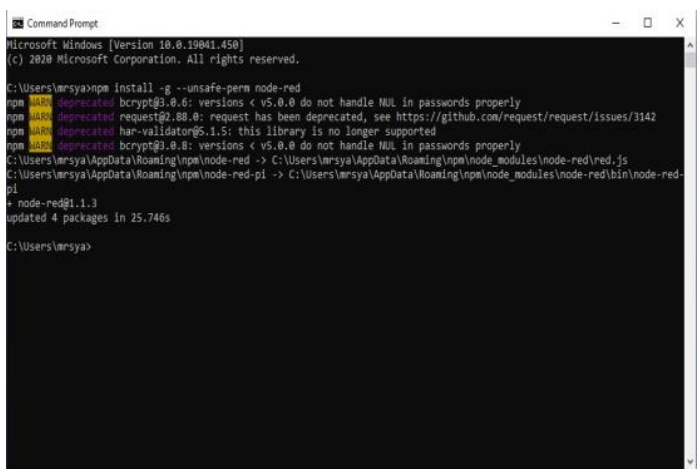

Gambar 5. Instalasi Node-Red

Jika instalasi sudah selesai maka cukup ketik node-red pada command prompt maka node-red akan aktif. Selanjutnya jika status nodered sudah running, maka jangan close command prompt agar node-red tetap aktif. Selanjutnya buka browser dan akses local IP atau localhost dengan port sesuai settingan node-red yaitu port 1880.

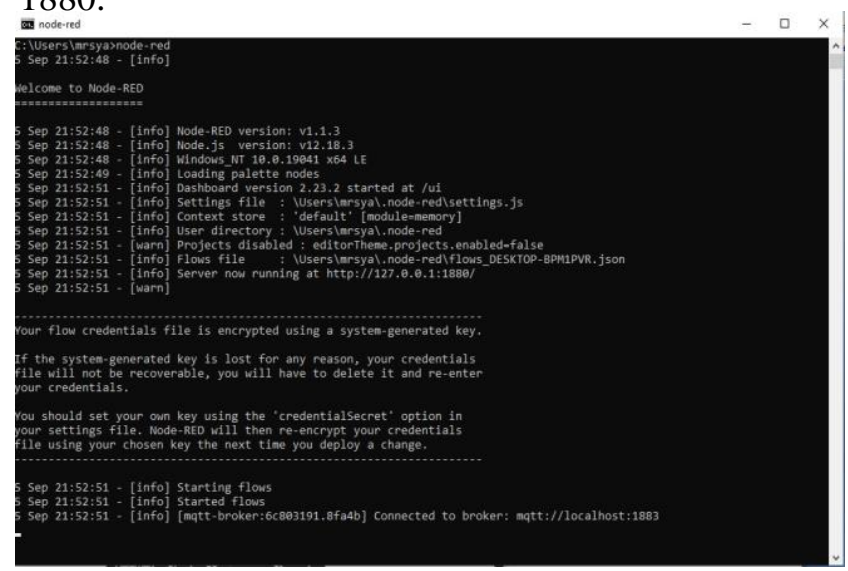

Gambar 6. Tampilan CMD menjalankan Node-Red

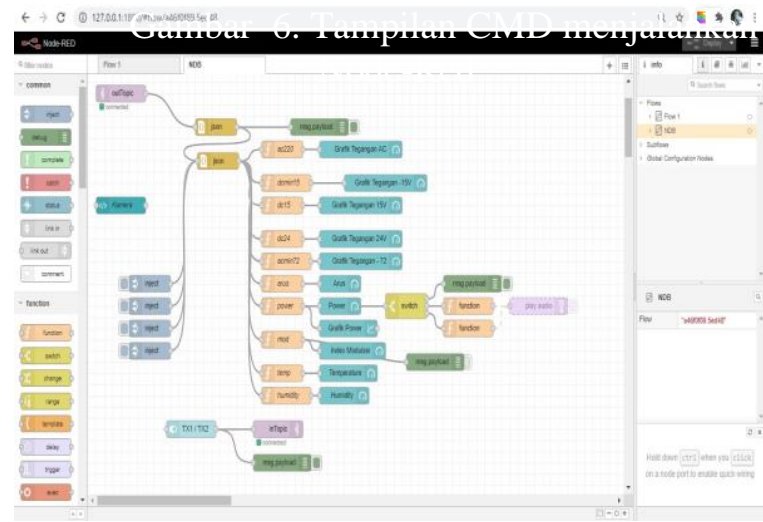

Gambar 7. Tampilan Menjalankan Node-Red

\subsection{Implementasi Dashboard Monitoring}

Untuk memonitoring status masingmasing sensor serta kondisi ruangan penulis membuat tampilan menggunakan mqtt dashboard.

Tampilan pertama berbentuk line chart dengan fungsi mengeluarkan status nilai dari masing-masing sensor yang sedang dalam keadaan aktif atau mendeteksi inputan. Line Chart tersebut akan menampilkan warna sesuai dengan nilai yang kita atur berdasarkan standar yang sudah ditetapkan dimanual operasi peralatan NDB Hanjin KMW 250 RB.

Tabel 2. Parameter Toleransi NDB Hanjin KMW $250 \mathrm{RB}$

\begin{tabular}{|c|c|c|c}
\hline Parameter & $\begin{array}{c}\text { Kuning } \\
\text { (Dibawah } \\
\text { Toleransi) }\end{array}$ & $\begin{array}{c}\text { Hijau } \\
\text { (Didalam } \\
\text { Toleransi) }\end{array}$ & $\begin{array}{c}\text { Merah } \\
\text { (Diluar Tolerans }\end{array}$ \\
\hline $220 \mathrm{~V}$ & $<=200 \mathrm{~V}$ & $>200 \mathrm{~V}$ s.d $<240 \mathrm{~V}$ & $=240 \mathrm{~V}$ \\
\hline$-72 \mathrm{~V}$ & $<=-65 \mathrm{~V}$ & $>-65 \mathrm{~V}$ s.d $<-98 \mathrm{~V}$ & $=>-98 \mathrm{~V}$ \\
\hline $24 \mathrm{~V}$ & $<=20 \mathrm{~V}$ & $>20$ s.d $<28 \mathrm{~V}$ & $=>28 \mathrm{~V}$ \\
\hline $15 \mathrm{~V}$ & $<=12 \mathrm{~V}$ & $>12 \mathrm{~V}$ s.d $<18 \mathrm{~V}$ & $=>18 \mathrm{~V}$ \\
\hline$-15 \mathrm{~V}$ & $<=-12 \mathrm{~V}$ & $>-12 \mathrm{~V}$ s.d $<-18 \mathrm{~V}$ & $=>-18 \mathrm{~V}$ \\
\hline Power & $-3 \mathrm{~dB}$ & $50-100 \mathrm{~W}$ & $+3 \mathrm{~dB}$ \\
\hline Modulasi & $<=70 \%$ & $>70 \%$ s.d $<90 \%$ & $=>90 \%$ \\
\hline
\end{tabular}




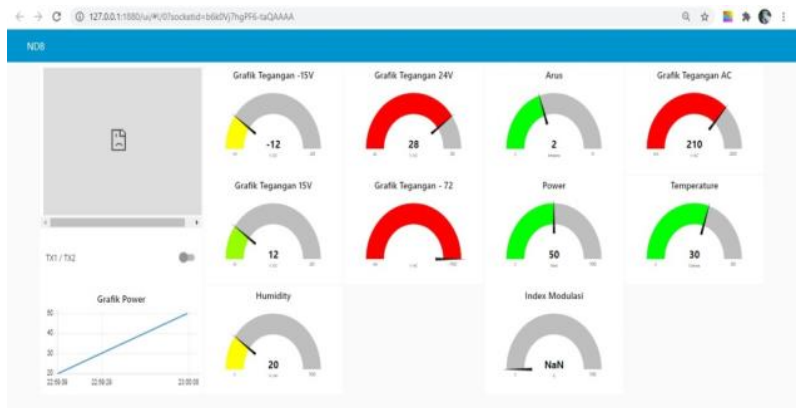

Gambar 8 Tampilan pengujian dalam kondisi 1 menggunakan inject yang menampilkan semua kondisi

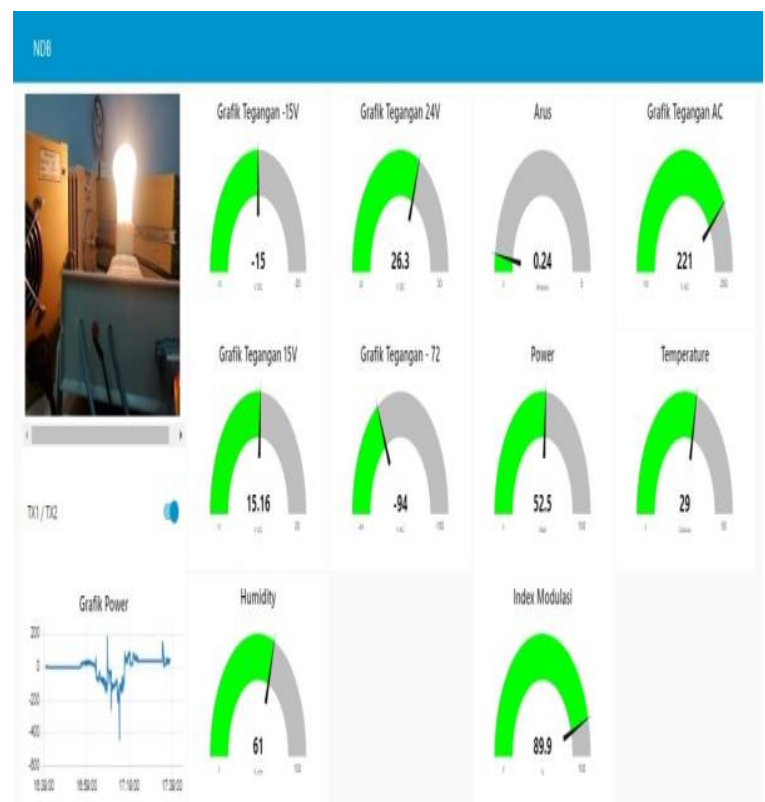

Gambar 9. Tampilan Uji actual berdasarkan nilai pembacaan dari masing-masing sensor

Pada gambar 9 merupakan uji coba menggunakan inject pada mqtt dashboard dengan nilai sebagai berikut : $\quad\{$ "ac220":210, "dcmin15":-12, "dc15":12, "dc24":28, "dcmin72":-75, "arus":2, "power":50, "temp":30, "humidity":20\}, sehingga nilai dari semua parameter yang disimulasikan menampilkan semua indikator toleransi yang sudah ditetapkan sebelumnya. Sedangkan gambar 4.6 menampilkan nilai aktual berdasarkan dari pembacaan masing-masing sensor yang diambil secara realtime, di mana sudah dilakukan kalibrasi dan pembandingan dengan menggunakan alat ukur multimeter.

\subsection{Pengujian Sistem}

Mirokontroler membaca nilai analog dari semua sensor NDB, selanjutnya data analog dikonversi dalam bentuk ADC. Data kemudian dikirim melalui ethernet shield
Airman: Jurnal Teknik dan Keselamatan Transportasi Volume 3 Nomor 2 Desember 2020 P-ISSN 2622 - 0105 | E-ISSN 2716-1196

dengan menggunakan protokol MQTT ke server broker dengan alamat address yang diinput yaitu : 192.168.4 3.11:1883, disisi server dipasangkan node-red yang terhubung ke Node-Red yang dapat diakses melalui port 1880. Dalam penelitian ini penulis menghubungkan server pada aplikasi Node-Red dibuat untuk mengkoneksikan ke mqtt broker untuk memonitoring data yang dikirim melalui mikrokontroler, maka data akan diterima dalam bentuk json lalu dipisahkan agar dapat divisualisasikan, untuk menampilkan pembacaan dari mikrokontroler maka dibuat user interface geuge (mengukur) dan chart garis (grafik).

Aplikasi ini pula dilengkapi notifikasi alarm peringatan berupa display informasi peringatan tampilan aplikasi dan suara dalam bentuk TTS (text to speach) apabila power berada di luar toleransi, TTS tersebut memanfaatkan Google Voice.

\subsection{Implementasi Pengujian}

Dalam penelitian ini menggunakan metode pengujian black box yaitu dimana hanya mengamati hasil eksekusi melalui data uji dan memeriksa fungsi dari perangkat, sehingga dilakukanlah pengujian yang diambil berdasarkan parameter-parameter yang sesuai dengan form meter reading dan ground check untuk peralatan NDB Hanjin KMW 250 RB. Pengujian akan dilakukan dengan membandingkan hasil dari pembacaan sensor-sensor dengan menggunakan alat ukur multimeter atau biasa disebut dengan AVO meter.

Berdasarkan hasil dari pengujian masing-masing sensor dan perbandingan nilai dari alat ukur multimeter, maka bisa disimpulkan hasil masih didalam toleransi diperalatan NDB Hanjin KMW 250 RB yang sudah dijelaskan di 4.3 Implementasi Dashboard Monitoring. 


\begin{tabular}{|c|c|c|c|c|c|}
\hline No. & Nama & $\begin{array}{c}\text { Yang } \\
\text { Diharankan }\end{array}$ & $\begin{array}{c}\text { Hasil } \\
\text { Pembacaan }\end{array}$ & $\begin{array}{c}\text { Hasil } \\
\text { Pengukuran }\end{array}$ & $\begin{array}{c}\text { Error } \\
(\%)\end{array}$ \\
\hline \multirow{3}{*}{1.} & \multirow{3}{*}{ Voltage Divider } & $24 \mathrm{Vdc}$ & $26.3 \mathrm{Vdc}$ & $26.77 \mathrm{Vdc}$ & $1.7 \%$ \\
\hline & & $15 \mathrm{Vdc}$ & $15.16 \mathrm{Vdc}$ & $15.22 \mathrm{Vdc}$ & $0.3 \%$ \\
\hline & & $.15 \mathrm{Vdc}$ & $.15 \mathrm{Vdc}$ & $-15.14 \mathrm{Vdc}$ & $0.9 \%$ \\
\hline \multirow{3}{*}{2.} & \multirow{3}{*}{ Sensor AC } & $220 \mathrm{Vac}$ & $221 \mathrm{Vac}$ & $225 \mathrm{Vac}$ & $1.7 \%$ \\
\hline & & & & & \\
\hline & & $.72 \mathrm{Vac}$ & $.94 \mathrm{Vac}$ & $.92 \mathrm{Vac}$ & $2.1 \%$ \\
\hline 3. & Sensor Arus & - & $0.24 \mathrm{~A}$ & $0.3 \mathrm{~A}$ & $20 \%$ \\
\hline 4. & SensorDHT 11 & - & $27^{\circ} \mathrm{C}$ & $27^{\circ} \mathrm{C}$ & 0 \\
\hline
\end{tabular}

Tabel 3. Hasil pembacaan sensor dan alat ukur

\subsection{Flowchart}

Flowchart sistem berfungsi untuk mempermudah memahami cara kerja program pada sistem yang dibuat. Flowchart sistem dapat dilihat pada gambar 10 dibawah
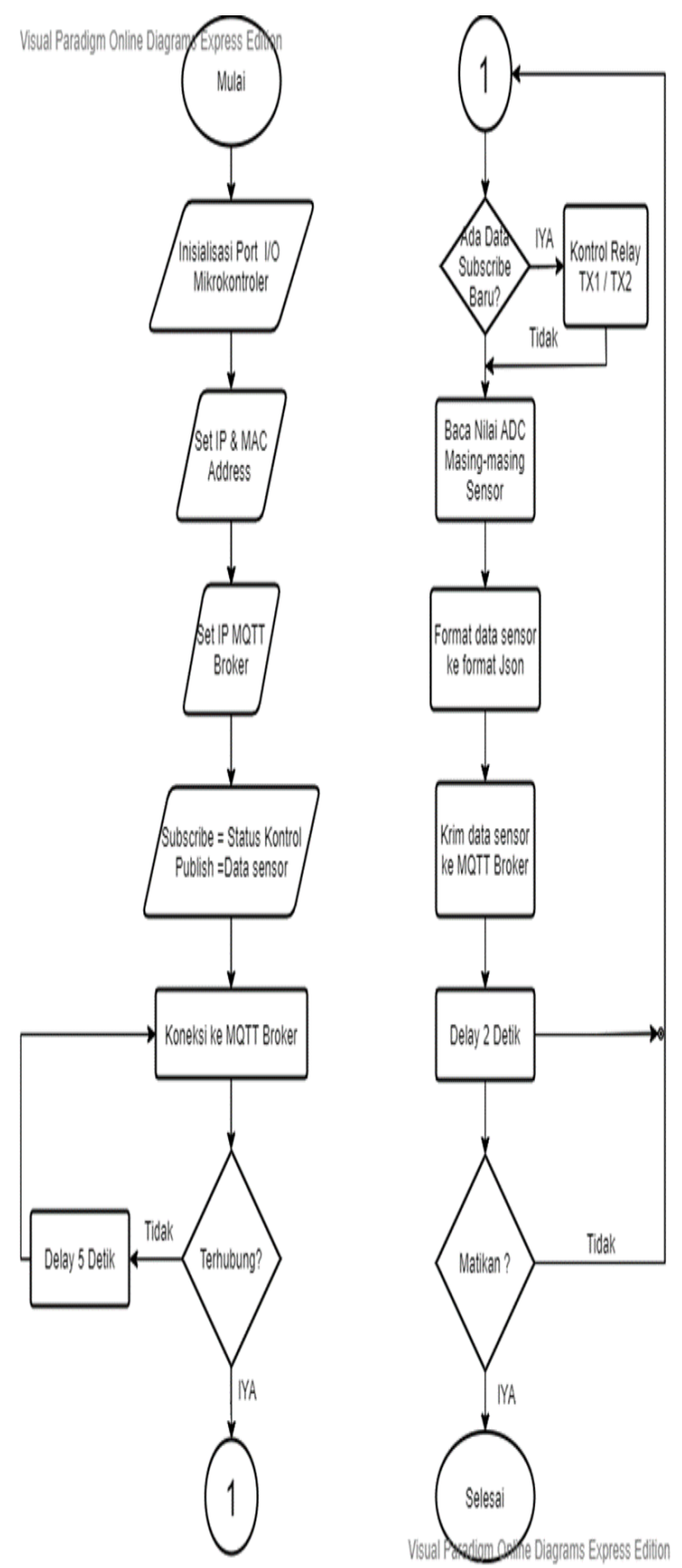

Gambar 10. Flowchart

\section{KESIMPULAN}

Dari hasil penelitian serta pembahasan yang telah dipaparkan dapat disimpulkan sebagai berikut:

a. Parameter yang diambil dalam melakukan monitoring mengggunakan RCMS untuk peralatan NDB Hanjin KMW 250 RB yaitu mengacu pada skep 83 tahun 2005 dan KP 35 tahun 2019 
seperti melakukan pengecekkan parameter tegangan $220 \mathrm{~V}, 24 \mathrm{~V}, 15 \mathrm{~V}$, $15 \mathrm{~V},-72 \mathrm{~V}$, arus, modulasi, power, suhu, dan melakukan perpindahan transmitter.

b. Dalam melaksanakan unjuk kerja sensor dan aktuator pada implementasi RCMS dilihat dari perbandingan nilai pembacaan sensor dengan alat ukur multimeter dengan hasil pembacaan nilai dari sensor tegangan $24 \mathrm{~V}$ terbaca $26.3 \mathrm{~V}$ sedangkan pada alat ukur $26.77 \mathrm{~V}$, tegangan $15 \mathrm{~V}$ terbaca $15.16 \mathrm{~V}$ alat ukur $15.22 \mathrm{~V}$, tegangan $-15 \mathrm{~V}$ terbaca $15 \mathrm{~V}$ alat ukut $-15 \mathrm{~V}$, tegangan $-72 \mathrm{~V}$ terbaca $-94 \mathrm{~V}$ alat ukur $-92 \mathrm{~V}$, tegangan $220 \mathrm{~V}$ terbaca $221 \mathrm{~V}$ alat ukur $225 \mathrm{~V}$, sensor arus terbaca 0.24 A sedangkan alat ukur $0.3 \mathrm{~A}$, sensor suhu terbaca $27 \mathrm{OC}$ alat ukur 27OC. Dalam memonitoring kondisi sekitar dan melakukan perpindahan transmitter bekerja dengan baik.

c. Performance RCMS pada pengimplementasian diteknologi IOT berkerja dengan baik, dilihat dari pembacaan parameter-parameter yang dicuplik oleh masing-masing sensor yang ditampilkan

d. RCMS secara real time dan responsivenya perubahan nilai-nilai dari sensor tersebut.

\section{DAFTAR PUSTAKA}

A. Fitriandi, E. Komalasari, and H. Gusmedi, "Rancang Bangun Alat Monitoring Arus dan Tegangan Berbasis Mikrokontroler dengan SMS Gateway, " J. Rekayasa dan Teknol. Elektro, vol. 10, no. 2, pp. 8798, 2016

Adam, Hikmahtul Amri, Miswan, 2019. Sistem Monitoring Arus dan Tegangan Menggunakan SMS Gateway

Angga Riantiarto, Dedy Suryadi, Saifurrahman, 2019. Rancang Bangun
Alat Monitoring Arus Pada Beban Listrik Rumah Tangga Menggunkan Web Berbasis Arduino uno R3

Afrizal, Fitriandi, 2016. Rancang Bangun Alat Monitoring Arus dan Tegangan Berbasis Mikrokontroler dengan SMS Gateway

Balaji Sivasubramanian, Erum Frahim, Richard Froom, 2010. Analyzing the Cisco Enterprise Campus Architecture, https://www.ciscopress.com /articles/article.asp? $\mathrm{p}=1608131 \&$ seq $\mathrm{Nu}$ $\mathrm{m}=3$. Diakses 18 Mei 2020

B. Stewart, Adventures in Arduino. united kingdom: John Wiley and Sons,Ltd, 2015.

Dwi Wahyu Suryawan, 2012. Rancang Bangun Sistem Monitoring Tegangan, Arus dan Temperatur pada Sistem Pencatu Daya Listrik di Teknik Elektro Berbasis Mikrokontroler Atmega 128

KP 35 tahun 2019. Prosedur Pemeliharaan dan Pelaporan Fasilitas Telekomunikasi Penerbangan. Diakses 18 Mei 2020

P. Sciencedirect, "ScienceDirect ScienceDirect Faults Monitoring System in the Electric Power Grid of Medium Faults Monitoring System in the Electric Power Grid of Medium Voltage Voltage," Procedia Comput. Sci., vol. 130, pp. 696-703, 2018.

Roy Blake, Wireless Communication Technology, 2001, USA: Delmar

SKEP/83/VI/2005. Prosedur pengujian di darat (Ground Inspection) peralatan Elektronika dan Listrik Bandara. Diakses 18 Mei 2020.

Yasha, 2018., Internet of Things, Panduan Lengkap. Diperoleh dari: https://www.dewaweb.com/blog/inter net-of-things/. Diakses 18 Mei 2020 
Jamaluddin Rahim, Junaedi. Rancangan system monitoring indicator led transmitter ils di bandar udara tjilik riwut palangkaraya, Vol. 1 No. 1 (2018) 32-41, AIRMAN: Jurnal Teknik dan Keselamatan Transportasi

Abdul Azis, Rio Setiawan. rancangan antenna penerima automatic dependent surveillance broadcast dengan frekuensi $1090 \mathrm{mhz}$ mengguanakan rtl820t, Vol. 2 No. 1 (2019) 6-11 AIRMAN: Jurnal Teknik dan Keselamatan Transportasi 